\title{
Modern Trends in Induction Accelerator Technology
}

\author{
G. J. Caporaso
}

This article was submitted to US-CERN-Japan-Russia Joint Accelerator School, Long Beach, CA, November 6-14, 2002

\section{June 17, 2003}

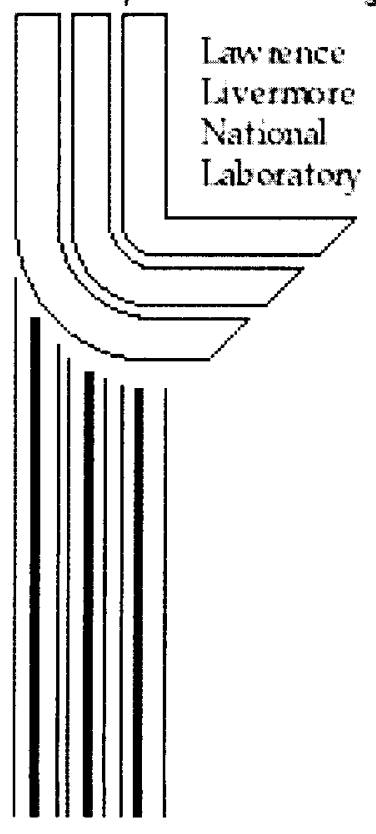




\section{DISCLAIMER}

This document was prepared as an account of work sponsored by an agency of the United States Government. Neither the United States Government nor the University of California nor any of their employees, makes any warranty, express or implied, or assumes any legal liability or responsibility for the accuracy, completeness, or usefulness of any information, apparatus, product, or process disclosed, or represents that its use would not infringe privately owned rights. Reference herein to any specific commercial product, process, or service by trade name, trademark, manufacturer, or otherwise, does not necessarily constitute or imply its endorsement, recommendation, or favoring by the United States Government or the University of California. The views and opinions of authors expressed herein do not necessarily state or reflect those of the United States Government or the University of California, and shall not be used for advertising or product endorsement purposes.

This is a preprint of a paper intended for publication in a journal or proceedings. Since changes may be made before publication, this preprint is made available with the understanding that it will not be cited or reproduced without the permission of the author.

This work was performed under the auspices of the United States Department of Energy by the University of California, Lawrence Livermore National Laboratory under contract No. W-7405-Eng-48.

This report has been reproduced directly from the best available copy.

Available electronically at http://www.doc.gov/bridge

Available for a processing fee to U.S. Department of Energy

And its contractors in paper from

U.S. Department of Energy

Office of Scientific and Technical Information

P.O. Box 62

Oak Ridge, TN 37831-0062

Telephone: (865) 576-8401

Facsimile: (865) 576-5728

E-mail: reports@adonis.osti.gov

Available for the sale to the public from

U.S. Department of Commerce

National Technical Information Service 5285 Port Royal Road Springfield, VA 22161

Telephone: (800) 553-6847

Facsimile: (703) 605-6900

E-mail: orders@ntis.fedworld.gov

Online ordering: http://www.ntis.gov/ordering.htm

\section{OR}

Lawrence Livermore National Laboratory

Technical Information Department's Digital Library

http://www.llnl.gov/tid/Library.html 


\title{
MODERN TRENDS IN INDUCTION ACCELERATOR TECHNOLOGY*
}

\author{
G.J. CAPORASO \\ Lawrence Livermore National Laboratory \\ P.O. Box $808, L-645$ \\ Livermore, CA 94550, USA \\ E-mail: caporasolellnl.gov
}

\begin{abstract}
Recent advances in solid-state modulators now permit the design of a new class of high current accelerators. These new accelerators will be able to operate in burst mode at frequencies of several $\mathrm{MHz}$ with unprecedented flexibility and precision in pulse format. These new modulators can drive accelerators to high average powers that far exceed those of any other technology and can be used to enable precision beam manipulations. New insulator technology combined with novel pulse forming lines and switching may enable the construction of a new type of high gradient, high current accelerator. Recent developments in these areas will be reviewed.
\end{abstract}

\section{Introduction}

\subsection{Induction Accelerator Operating Principle}

Let us consider the operation of a single induction accelerator cell. An external source of pulsed power is coupled into the cell from (usually) two or more coaxial cables. There is a magnetically permeable core inside the cell. The core is generally composed of ferrite or tape wound materials such as Metglas (from Honeywell) or Finemet (from Hitachi Metals).

The induction cell has the interesting characteristic that the outside of it is at ground potential while it is operating; voltage is only present on the inside of the cell. This characteristic is made possible by the presence of the core material, which presents a high inductance path for leakage currents, which flow around the core along a DC, short-circuit path inside the cell. The actual behavior of the core is much more complicated but this simple picture will suffice to illustrate the operating principle of the cell. The core will present a high impedance as long as it isn $t$ saturated. Once saturated, the core impedance

\footnotetext{
- This work was performed under the auspices of the U.S. Department of Energy by the University of California, Lawrence Livermore National Laboratory under Contract No. W-7405-Eng-48.
} 
collapses to a small value and the leakage current increases dramatically shutting off the accelerating voltage. A typical core hysteresis plot is shown in Figure 1.

B

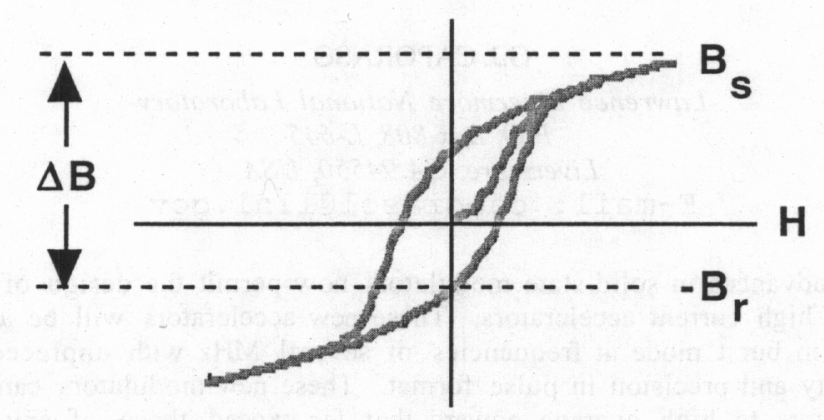

Figure 1. A typical B-H curve showing the results of a cyclical magnetization of the core. $\mathrm{B}_{\mathrm{s}}$ is the saturation value of the core and $\mathrm{B}_{\mathrm{r}}$ is the remnant magnetization, the value of the internal field when the external excitation is reduced to zero. $\Delta B$ is $\mathrm{B}_{\mathrm{s}}+\mathrm{B}_{\mathrm{r}}$ since the core is generally reset before pulsing to allow a greater flux swing.

The core is usually driven into saturation in the opposite direction prior to application of the accelerating voltage. This is referred to as resetting the core. When the reset pulse is removed the magnetization decays to the remnant value $\mathrm{B}_{\mathrm{r}}$. The total flux swing then available to the core is $\mathrm{B}_{\mathrm{s}}$, the saturated value + $\mathrm{B}_{\mathrm{r}}$. The voltage pulse that comes into the cell from the drive cables is applied around a path that encircles the core and along a path that drives a vacuum gap. The accelerating field appears across this vacuum gap and can be sustained as long as the current that flows around the path encircling the core is relatively small. That will be the case as long as the core is not saturated. Upon saturation the core inductance is reduced to a very small value as the magnetic domains in the material are all aligned in the azimuthal direction and the effective permeability of the core is drastically reduced. The leakage current flowing around the core increases so much that it loads down the drive cable supplying power to the cell and the accelerating voltage collapses. pulse.

The core is then reset and the cell is ready for another accelerating voltage

A typical induction cell is shown in Figure 2. If we integrate Faraday s law around the dashed path shown in Figure 2. we find that

$$
\oint \vec{E} \cdot d \vec{\ell}=-\frac{d}{d t} \int_{S} \vec{B} \cdot d \vec{S}
$$


If we integrate both sides of Eq. (1) with respect to time assuming a constant voltage we find that

$$
V(\Delta t)=S(\Delta B)
$$

The left hand side of Eq. (2) is referred to as the volt-seconds of the core and shows the length of time that the core can sustain a particular gap voltage. Induction cells are usually used to produce pulses in the range of $20 \mathrm{~ns}$ up to several $\mu$ s. Typical $\Delta \mathrm{Bs}$ range from about 0.7 Tesla for ferrite up to 3.0 Tesla for MetGlas. $\mathrm{S}$ is the core cross-sectional area.

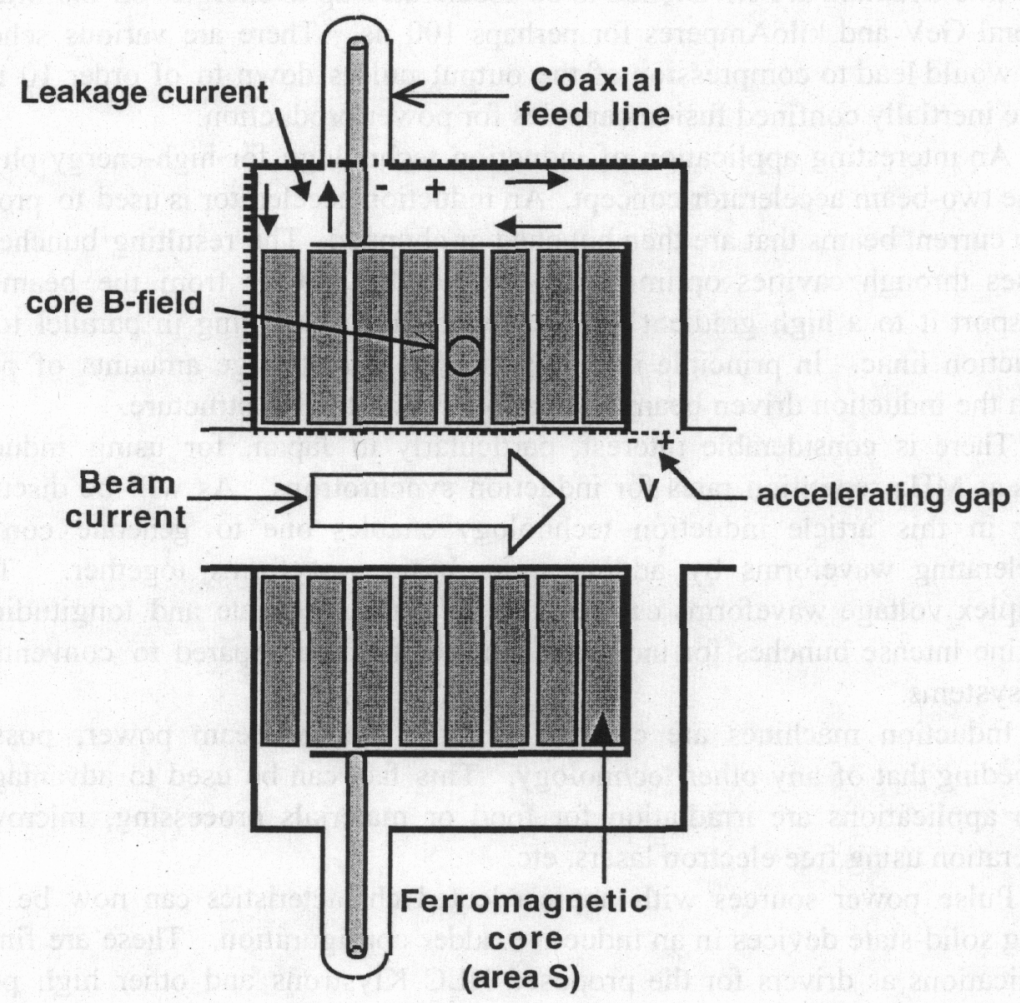

Figure 2. A typical induction cell showing a coaxial feed on the top and bottom along with a magnetic core. The voltage on the coaxial line is applied both around a path that encircles the core and one that leads to the accelerating gap. The applied voltage can exist across the gap as long as the core is not saturated. 


\subsection{Applications of Induction Technology}

Induction accelerators are usually used for applications requiring very high beam currents. One application that is the focus of activity in several countries is flash $\mathrm{x}$-ray radiography. These machines are used to $\mathrm{x}$-ray explosively driven dense objects where the high velocity of the objects requires brief but intense $x$ ray pulses. The recently constructed DARHT facility at Los Alamos, the AIRIX facility at Moronvilliers in France and the FXR facility at Livermore are examples of such machines. They typically provide pulses on the order of 20 $\mathrm{MeV}$ and several kiloAmperes for tens of ns.

Another high current application is Heavy Ion Fusion. Beams of heavy ions like Uranium are envisioned to be accelerated up to energies on the order of several $\mathrm{GeV}$ and kiloAmperes for perhaps $100 \mathrm{~ns}$. There are various schemes that would lead to compression of the output pulses down to of order $10 \mathrm{~ns}$ to drive inertially confined fusion capsules for power production.

An interesting application of induction technology for high-energy physics is the two-beam accelerator concept. An induction accelerator is used to produce high current beams that are then bunched or chopped. The resulting bunches are passes through cavities optimized to extract RF power from the beam and transport it to a high gradient RF accelerator that is running in parallel to the induction linac. In principle it is possible to extract large amounts of power from the induction driven beam and couple it into the RF structure.

There is considerable interest, particularly in Japan, for using induction cells at $\mathrm{MHz}$ repetition rates for induction synchrotrons. As will be discussed later in this article induction technology enables one to generate complex accelerating waveforms by adding more basic waveforms together. These complex voltage waveforms can be used to both accelerate and longitudinally confine intense bunches for increased luminosity as compared to conventional RF systems.

Induction machines are capable of high average beam power, possibly exceeding that of any other technology. This fact can be used to advantage in such applications are irradiation for food or materials processing, microwave generation using free electron lasers, etc.

Pulse power sources with unprecedented characteristics can now be built using solid-state devices in an inductive adder configuration. These are finding applications as drivers for the proposed NLC Klystrons and other high power systems.

\subsection{Some Early Pulsed Power Systems}

The first system we will consider is the Blumlein/spark gap system shown in Figure 3. A Marx bank or high voltage step up transformer is used to charge the Blumlein, which is a set of nested coaxial transmission lines (usually filled 
with water). Once charged a spark gap is used to short the center conductor to ground thus initiating the voltage pulse towards the induction cell.

\section{Blumlein}

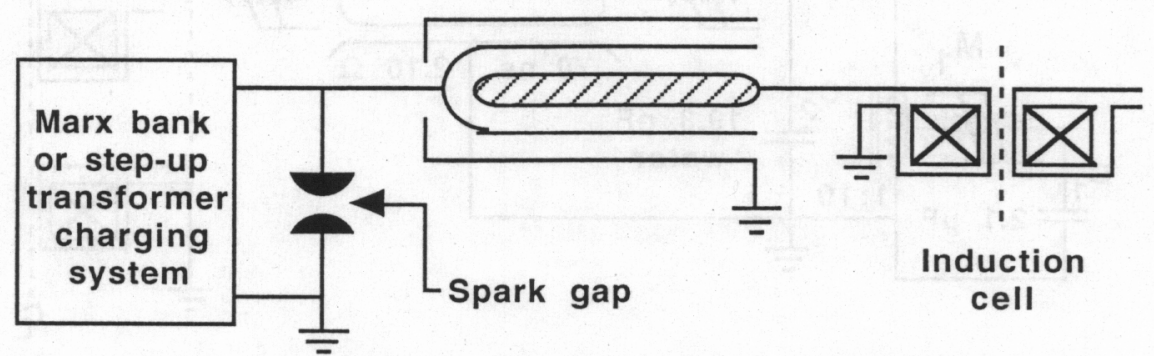

Figure 3. A Blumlein/spark gap system driving an induction cell. The Blumlein is charged either from a Marx bank or through a step-up transformer.

Such a system is used to power the FXR accelerator at Livermore and was used to power the now deactivated $50 \mathrm{MeV}, 10 \mathrm{kA}$ Advanced Test Accelerator at Livermore. An example from the FXR is shown in Figure 4.

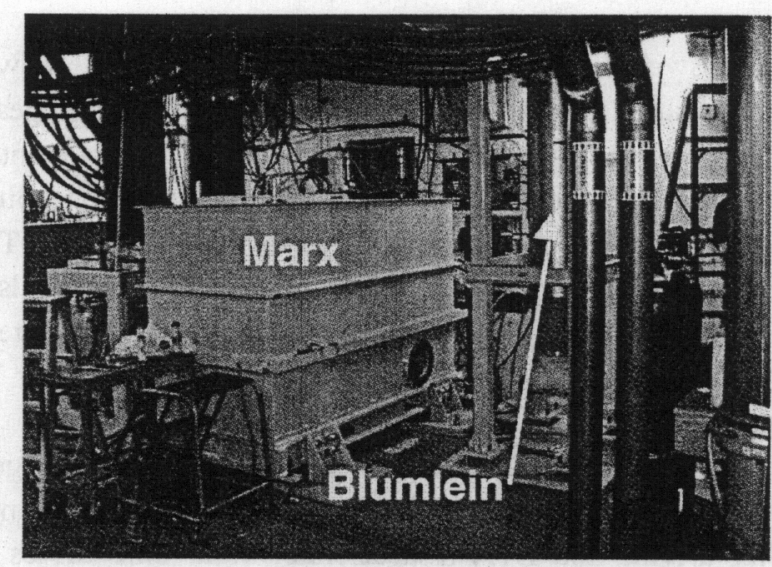

Figure 4. A picture of the FXR Marx bank (foreground left) and the Blumlein (back right).

A somewhat more modern development is the use of magnetic pulse compressor technology as shown in Figure 5. This system is used to power the ETA-II accelerator at Livermore. This system is capable of producing many millions of pulses without maintenance. ETA-II has produced 50 pulse bursts at several kiloHertz. 


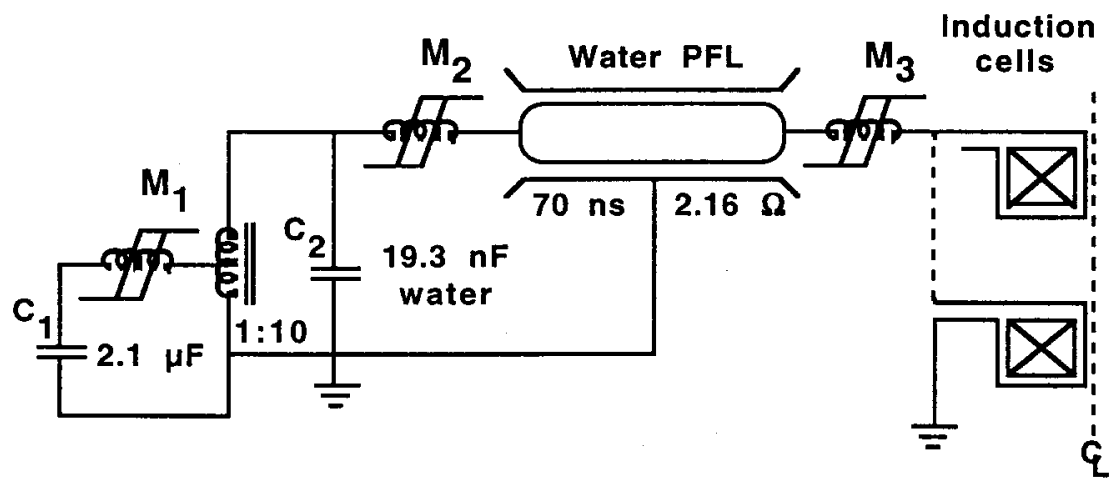

Figure 5. Partial schematic of a magnetic pulse compressor system. Saturable magnetic switches are used to transfer energy stored in the capacitance of the first stage and discharge it into the primary of a step-up transformer to charge another capacitor (C2). When the volt-seconds of the second magnetic switch M2 is exceeded it dumps the charge on $\mathrm{C} 2$ into a water filled pulse forming line. When the output switch M3 saturates, the energy in the pulse forming line is discharged through transmission lines to the induction cells.

A magnetic switch is simply a saturable magnetic core with a single encircling current path. Before the core saturates the switch appears as a high inductance. If a voltage is applied across the switch it prevents substantial current flow through the switch until its core saturates. At that point the switch has a very low inductance and it permits large currents to flow. This magnetic pulse compressor uses these switches to temporally compress pulses from one stage to another by reducing the L-C time constants of each stage. As can be seen from Figure 5. the output impedance of the compressor is very low permitting tens of kiloAmperes to flow into the load.

A picture of the MAG1-D pulse compressor is shown in Figure 6. This unit drives 20 ETA-II accelerator cells at $80 \mathrm{kV}$ and $2 \mathrm{kA}$ for $50 \mathrm{~ns}$. There are four such units driving the ETA-II accelerator (one unit drives the $1 \mathrm{MeV}$ injector and the other three each drive 20-cell sets). 


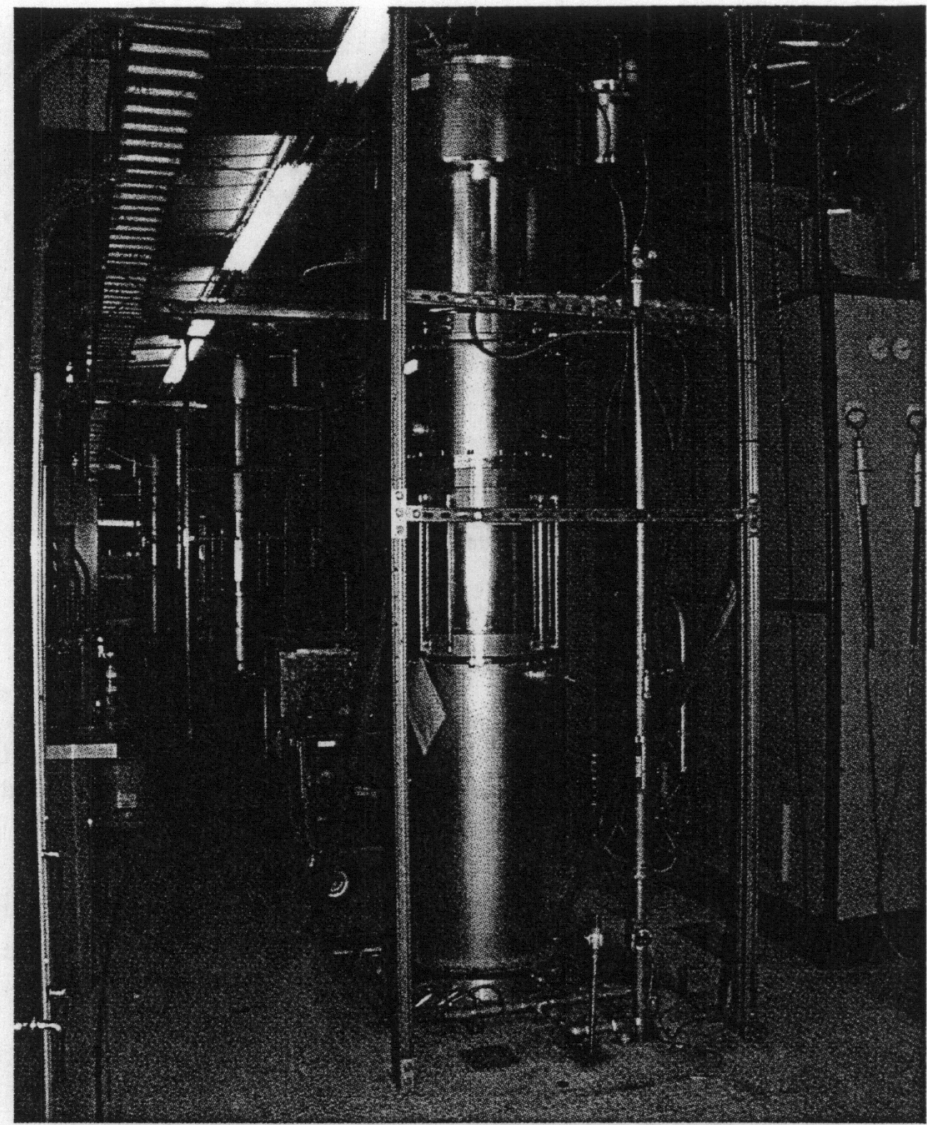

Figure 6. The MAG1-D pulse compressor, which drives 20 ETA-II induction cells at $80 \mathrm{kV}$ and $2 \mathrm{kA}$ for $50 \mathrm{~ns}$.

\section{Advanced Radiography as a Driver for New Technology}

Induction accelerators are widely used for flash x-ray radiography. Typically, these machines will produce a single pulse with a duration of tens of ns during a given hydrodynamic experiment. It was realized some years ago that by developing new pulsed power drivers it might be possible to build a single accelerator that could provide many pulses and many lines of sight during a single hydrodynamic experiment. ${ }^{1}$ A schematic of this concept is shown in Figure 7. 


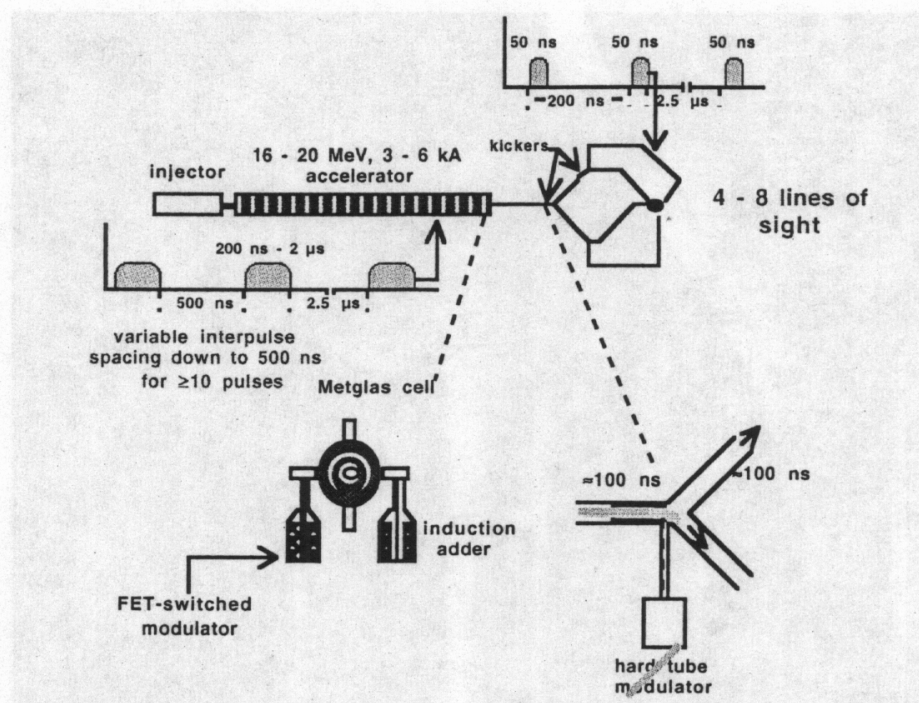

Figure 7. Advanced Radiography concept showing a single accelerator used to provide a rapid sequence of pulses that are subdivided by fast kickers to direct the resultant shorter pulses into different beam lines. Pulses of less than about $100 \mathrm{~ns}$ duration at the test object are required in order to avoid motion blur.

The technologies needed to make the concept of Figure 7. a reality are a pulsed power driver for induction cells capable of $\mathrm{MHz}$ repetition rate and an even faster modulator which variable waveform capability that can be used to drive a fast, high-current kicker system.

\subsection{Solid-State Modulator Concept}

The concept necessary to provide this capability is shown in Figure. 8. The system consists of a pre-charged capacitor bank and a suitable switch. The switch is in close proximity to the load, an induction cell, and connects and disconnects the capacitor bank from the load. A similar circuit with opposite polarity is used to reset the magnetic core in the induction cell. The load voltage and current waveforms are shown in the figure. At the conclusion of the reset phase the system is ready to provide another pulse. The switch is a series/parallel array of solid-state devices. 


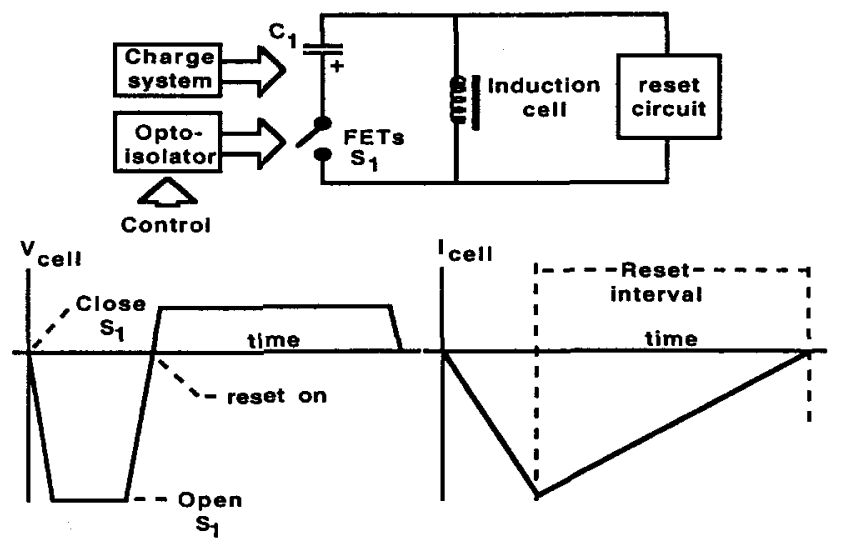

Figure 8. Solid-state modulator concept for high repetition rate operation.

\subsubsection{ARM Modulator}

The ARM (Advanced Radiographic Machine) modulator is shown in Figure 9. It is a prototype designed to drive an induction accelerator cell and to be stackable into an inductive adder configuration.

The modulator is built around a Metglas core. The primary and reset energy storage capacitors can be seen at the top of the modulator. Four series stacks of switching boards are arrayed around the core. Each stack consists of over 20 printed circuit boards, each containing 12 FETs in parallel. The circuit boards are arranged so that each FET is in series with the one directly above and below it in the stack. The FETs are optically commanded to open and close. The modulator has an open circuit voltage of $15 \mathrm{kV}$ and a nominal current rating of $4.8 \mathrm{kA}$. The modulator produces pulses ranging in width from $200 \mathrm{~ns}$ up to $2 \mu \mathrm{s}$ at repetition rates up to $2 \mathrm{MHz}$. 


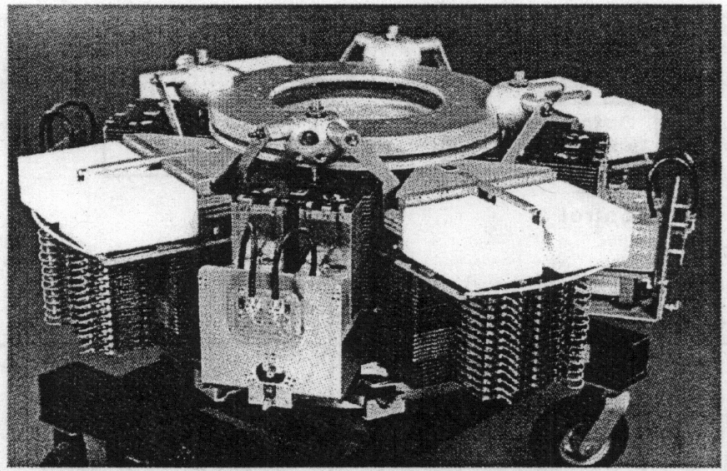

Figure 9. The ARM modulator; a stackable unit providing $15 \mathrm{kV}$ at $4.8 \mathrm{kA}$ at up to 2 $\mathrm{MHz}$ repetition rate.

These modulators can be stacked by threading the interior of the cores with a conducting stalk forming an inductive voltage adder. A three-stage adder is shown in Figure 10. The output of this device is $45 \mathrm{kV}$ at $4.8 \mathrm{kA}$ with the same pulse format capability as that of a single modulator.

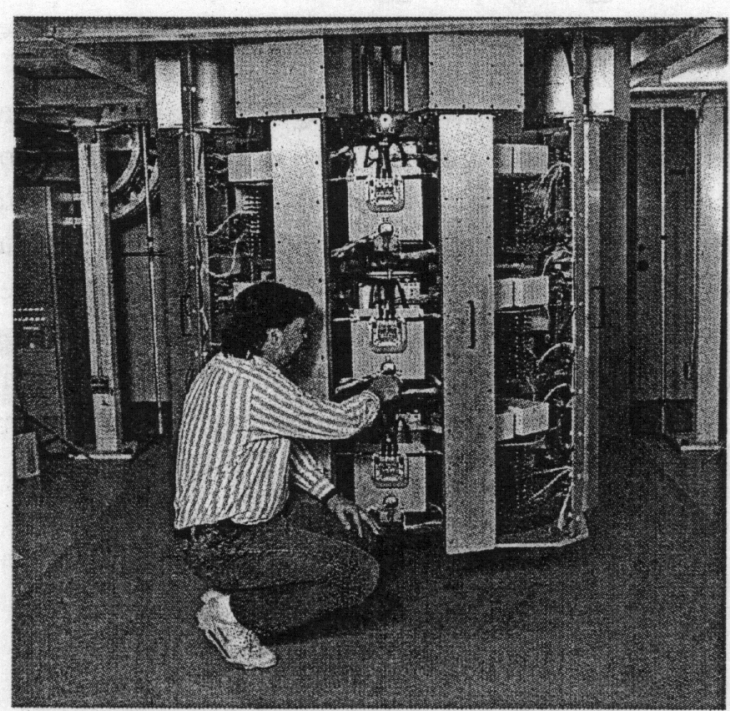

Figure 10. ARM 3-stage adder. The completed modulator is operated inside an oil tank for electrical insulation. The adder is shown here extracted for maintenance.

The output of the three-stage adder is shown in Figure 11. An essential capability of this architecture that cannot be overemphasized is the flexibility of the pulse format. It is possible to vary the width and inter-pulse interval from 
one pulse to the next easily from a computer or programmable waveform generator. Shown below is an example pulse train consisting of a $1 \mu \mathrm{s}$ pulse followed by 3,200 ns pulses followed by a $2 \mu$ s pulse, all with full reset. This prototype system fulfills the requirements of the Advanced Radiography concept shown in Figure 7.

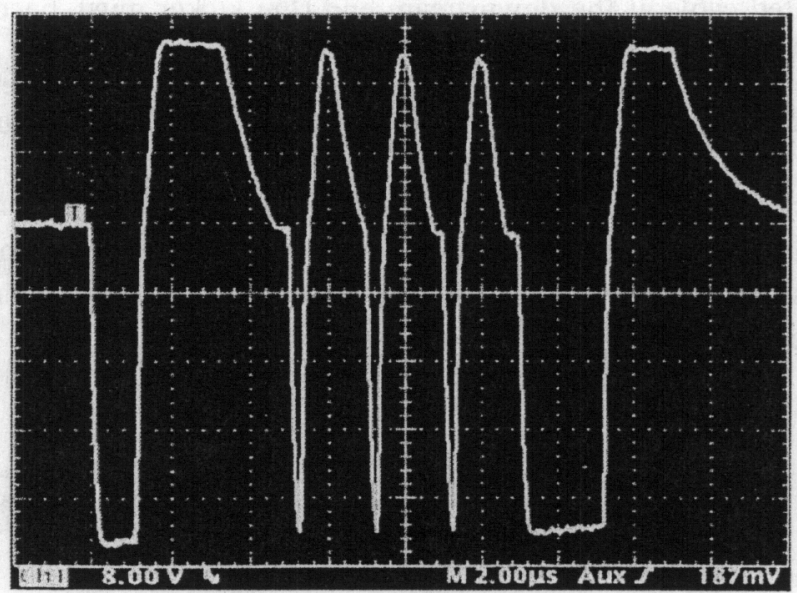

Figure 11. Example output waveform from the 3-stage adder. A 1-microsecond pulse with reset is followed by 3,200 nanosecond pulses (with reset) that are followed by a 2-microsecond pulse with reset.

This type of architecture lends itself readily to high average power applications for two reasons. First, the cores need not be driven anywhere near saturation in order for the system to work; they can be greatly oversized and segmented for cooling which would allow them to operate a high duty factors. Secondly, the switches are highly distributed since one FET is only capable of switching on the order of $100 \mathrm{~A}$ at about $1 \mathrm{kV}$ (the ARM modulator has over 2000 FETs). Each one of these can be heat-sinked and cooled.

\section{Fast, High-Current Kicker System}

The second piece of new technology needed for the Advanced Radiography concept shown in Figure 7. is a fast kicker system that can precisely steer high current, nearly continuous beams. 


\subsection{Fast Kicker System for High Current Beams}

In order to produce very fast steering the source of the electromagnetic fields applied to the beam must be inside the beam pipe. The architecture chosen is shown in Figure 12. It resembles that of a stripline beam position monitor. An outer vacuum housing surrounds four equal-sized electrodes. Each stripline is terminated at the upstream end by a resistor and is connected to a pulser through a time-isolated cable at the downstream end (the kicker must be driven at the downstream end or the electric and magnetic induced deflections of a relativistic electron beam will cancel). The kicker is operated as a $50 \Omega$ system with both the resistive terminations and the time isolation cables and the pulsers having impedances of $50 \Omega$.

The kicker must not only switch rapidly (in a time less than tens of ns) but it must be able to regulate the position of beams with great precision and without emittance growth as both of these are required to maintain good radiographic resolution from the accelerator.

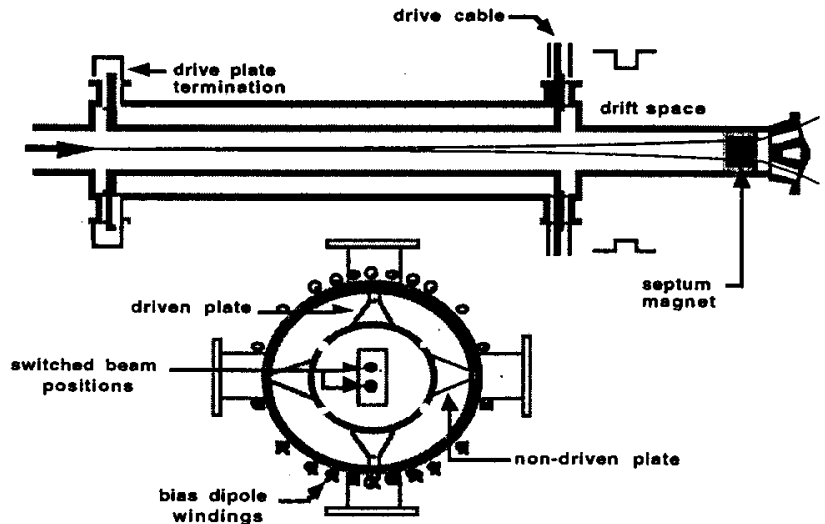

Figure 12. Fast kicker system is similar to a stripline beam position monitor. Steering is accomplished by a combination of electric and magnetic fields.

Because the pulser technology chosen to drive the kicker only has unipolar capability a DC bias dipole is wound around the outside of the kicker to extend the dynamic range of the beam centroid. A version used to deflect the $6 \mathrm{Mev}, 2$ kA beam from the ETA-II accelerator at LLNL is shown in Figure 13. 


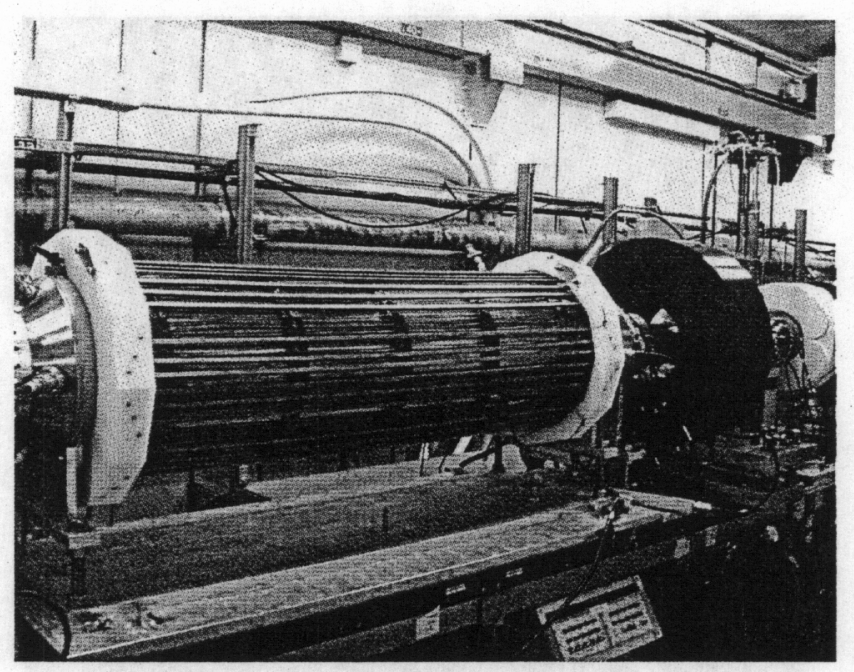

Figure 13. ETA-II kicker showing a DC bias dipole and a DC sextupole winding. The solenoid to the right of the kicker is the lens used to match the beam into the kicker. The drive cables can be seen on the left (downstream) side of the kicker. The kicker length is about 1.6 meters.

In order to regulate the position of the beam at the kicker output a pulser with a variable waveform capability is required. Part of the motivation for this is that there is beam-induced steering inside the kicker due to the high beam current. Another reason is due to head-to-tail energy variations in the beam that will cause dispersion. We will return to this point in section 3.4.

\subsection{Implementation in DARHT-2}

Some of this technology has found application in the $2^{\text {nd }}$ axis of DARHT. DARHT stands for Dual Axis Radiographic Hydrodynamic Test and consists of two induction accelerators. The $1^{\text {st }}$ axis is a conventional, single pulse machine producing about $20 \mathrm{MeV}$ at up to about $3 \mathrm{kA}$. It has been operating very successfully for several years. The $2^{\text {nd }}$ axis, now nearly complete, will produce a $2 \mu \mathrm{s}$ long pulse at up to $2 \mathrm{kA}$ and $18 \mathrm{MeV}$. 


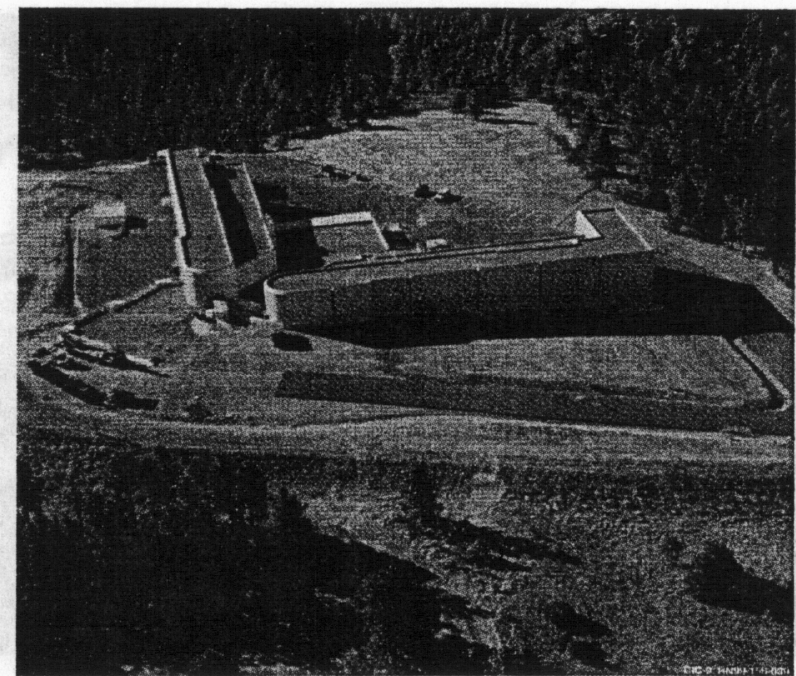

Figure 14. The DARHT facility at LANL. The $2^{\text {nd }}$ axis, shown on the right, is nearly complete. The $1^{\text {st }}$ axis has been operational for several years.

A kicker system is used to carve a sequence of four, relatively short pulses from the $2 \mu$ s beam exiting the accelerator. The unused beam is sent to a dump. The operational schematic is shown in Figure 15.

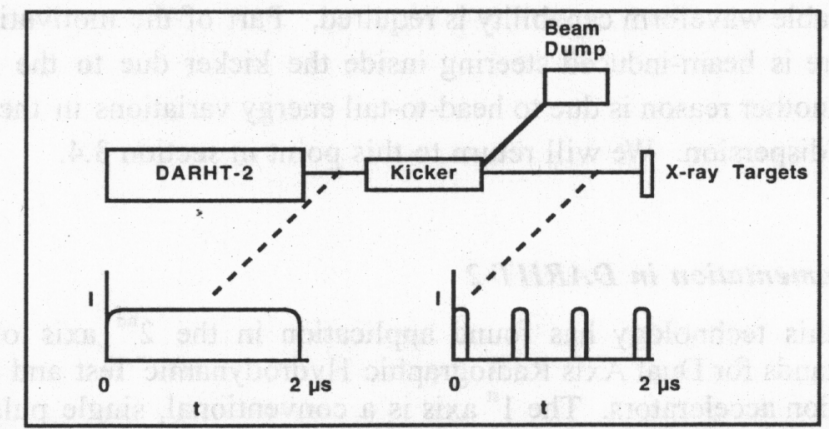

Figure 15. Concept of DARHT-2. A kicker system produces four radiographic pulses from a $2 \mu$ s beam exiting the accelerator.

The DARHT-2 accelerator uses Metglas cores in its massive induction cells. An electrostatic injector provides a beam with an energy up to about $3 \mathrm{MeV}$ and $2 \mathrm{kA}$. The kicker system is set up so that the bias dipole deflects the beam into the main dump until it receives drive pulses that allow the kicker fields to overcome the effects of the bias dipole and allow the beam to proceed to the $\mathrm{x}$ ray converter targets. A portion of the beam line is shown in Figure 16. 


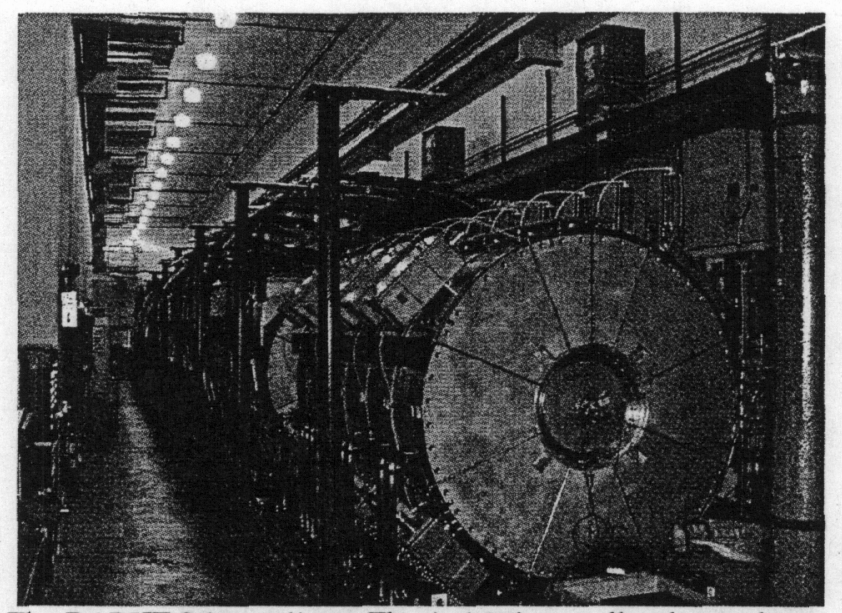

Figure 16. The DARHT-2 beam line. The induction cells shown here are nearly 2 meters in diameter.

\subsection{DARHT Kicker Pulser}

The kicker pulser is based on the solid-state architecture previously discussed. The actual implementation is highly modular with each switchboard having its own primary storage capacitor and Metglas core. Most of the layers are timed to produce a square output pulse. A number of the stages are charged to different levels and can be independently timed to produce a digital approximation to an analog waveform. Since the modulator is operated in an inductive adder configuration, the output voltage is the very nearly the sum of the voltages of all the individual layers.

The kicker pulsers for DARHT are required to produce up to $18 \mathrm{kV}$ into $50 \Omega$ with a $20 \%$ modulational capability. The pulsers power the kicker through large, low loss cables that provide $2 \mu$ s worth of time isolation to prevent any reflections or beam induced signals from perturbing the beam. A simplified schematic showing three digital stages and one equivalent analog layer is shown in Figure 17. 


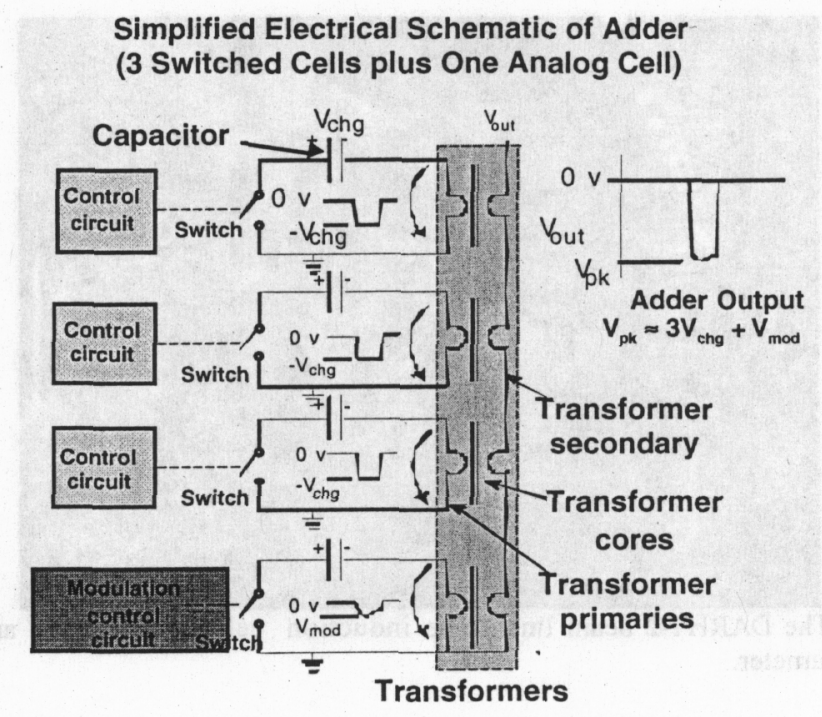

Figure 17. Simplified schematic of inductive adder kicker pulser showing 3 of many digital stages and a single modulation layer. The actual modulation is accomplished by using 7 digital stages charged to different voltages and independently timed.

The final modulator system for DARHT-2 is shown in Figure 18. It consists of a positive and negative polarity pulser (one for each opposing stripline to provide steering in the vertical plane) and a control rack in the center. The output cables to the kicker come out of the top of each pulser.

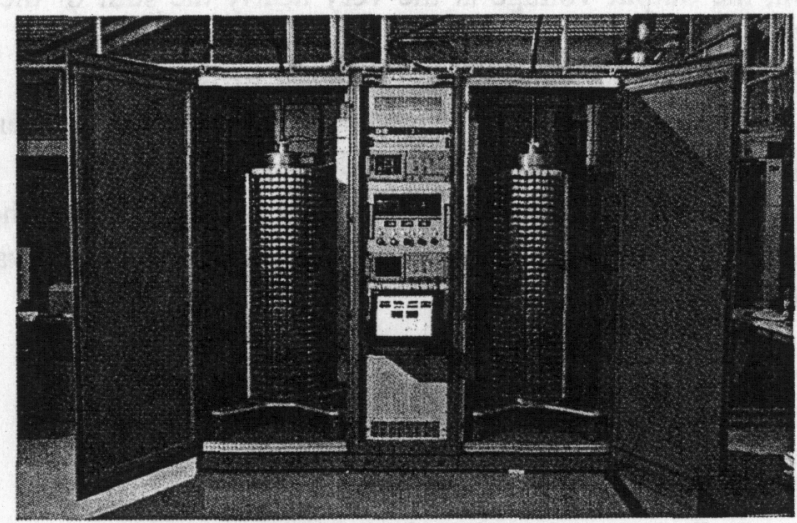

Figure 18. The completed DARHT-2 kicker pulser system. There are two $18 \mathrm{kV}$ pulsers, one of each polarity, which drive $50 \Omega$ cables. 
The completed pulsers are capable of generating variable width and variable shape pulse trains. An example burst of 4 pulses is shown in Figure 19. (DARHT is required to produce 4 equally spaced pulses of variable width).

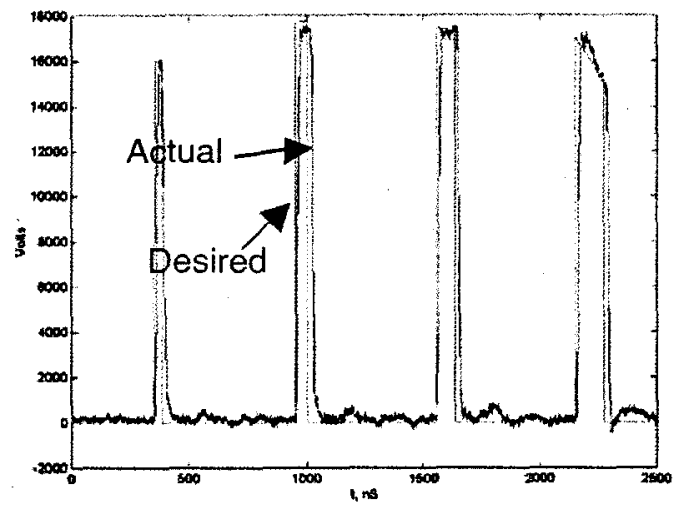

Figure 19. An example pulse format from the DARHT kicker pulser system. Note the variable width and variable shape output waveforms. Two sets of curves are shown; the desired waveform initially requested by the control system and the actual output voltages.

The kicker has been extensively tested on the ETA-II accelerator. ${ }^{2}$ Quick switching of the beam centroid has been accomplished without emittance growth for a $6 \mathrm{MeV}, 2 \mathrm{kA}$ beam with a pulsewidth of $50 \mathrm{~ns}$.

It should be noted that by driving all four striplines (and using two bias dipoles, one for each plane) steering may be achieved over the entire transverse plane. Furthermore, if one changes the polarity of one of the pulsers in the simple dipole mode, a fast, adjustable quadrupole lens may be realized. Figure 20 shows a single ETA-II pulse caught in the act of switching centroid positions while Figure 21. shows the resulting elliptical shape of a beam downstream of the kicker when the polarity of one the pulsers is reversed to make a quadrupole lens. 


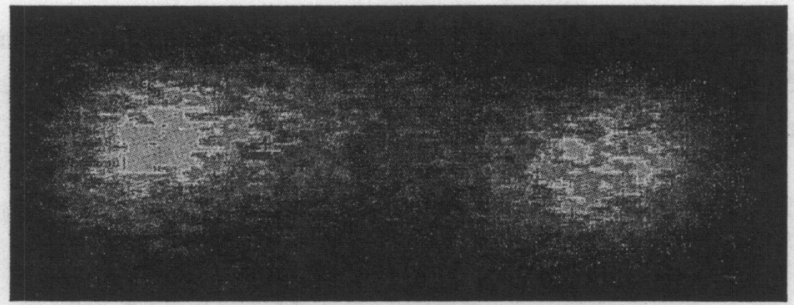

Figure 20. A single $50 \mathrm{~ns}$ beam pulse caught in the act of switching centroid positions. The picture is made from light emitted when the beam strikes a quartz foil downstream of the kicker. The total shift of centroid position is $4 \mathrm{~cm}$.

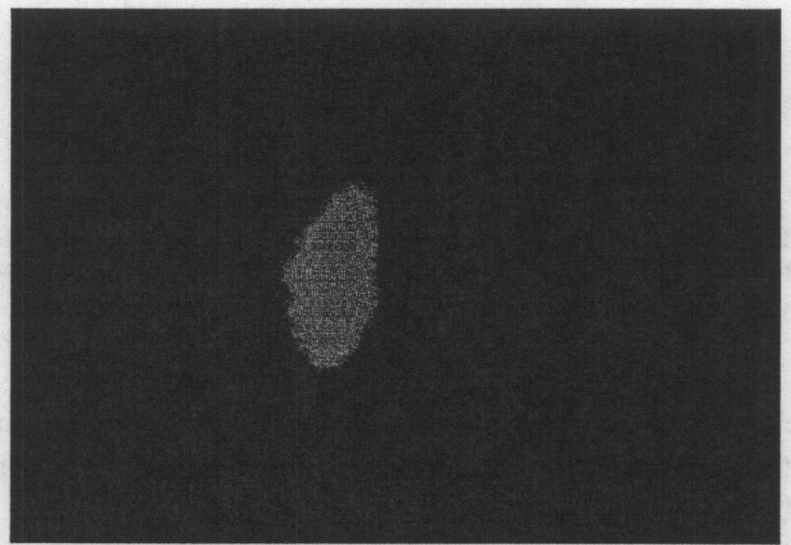

Figure 21. A time-integrated image of light produced when the electron beam strikes a quartz foil downstream of the kicker configured to produce a quadrupole field.

\subsection{DARHT Kicker Pulser Control System}

The kicker regulates the switched beam centroid position through use of a feed forward control system. An inner control loop determines a desired waveform to apply to the kicker electrodes. The actual waveform is measured and the loop iterates until the measured waveform corresponds to the desired one. Simultaneously, an outer control loop looks at the position of the beam downstream of the kicker as a function of time and uses an algorithm to derive a theoretical waveform that should result in the desired position. The outer loop feeds this information to the inner loop and the resulting beam position is measured on the next pulse. This loop iterates until the desired beam positional accuracy is obtained. In practice the outer loop converges in just a few beam pulses. 


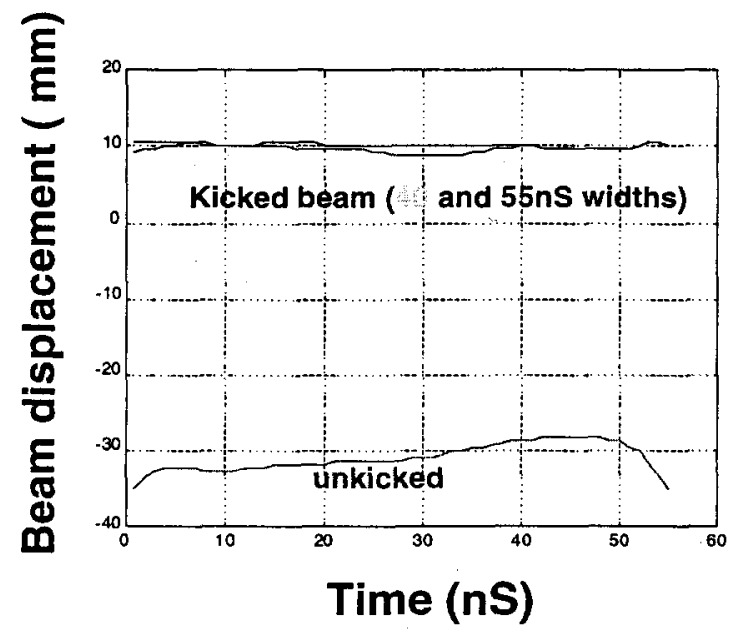

Figure 22. Plot of converged kicked beam position vs. time along with plot of beam position vs. time for beam entering the kicker. The switched beam position is successfully regulated to within $1 \mathrm{~mm}$ of the desired value.

\section{Proton Radiography Kicker Pulser}

There is a radiographic technique that requires very high-energy protons (of order 20 to $50 \mathrm{GeV}$ ). ${ }^{3}$ The system uses storage rings and requires fast kickers to extract pulses. The architecture developed for DARHT-2 is ideally suited for this application because of its inherent speed, flexibility and modularity. A prototype $50 \mathrm{kV}$ pulser for this application is shown in Figure 23. The pulser drives a $50 \Omega$ cable and must produce a 10-pulse burst at $2 \mathrm{MHz}$. 
20

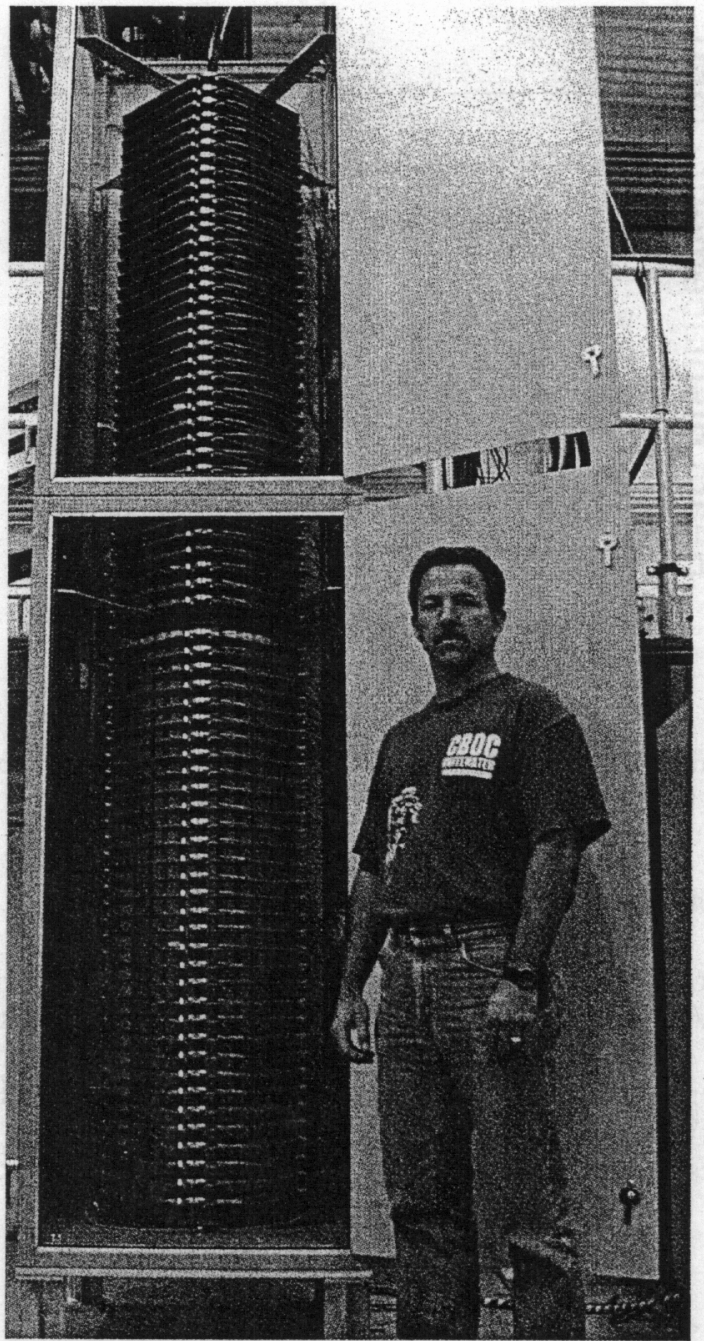

Figure 23. $50 \mathrm{kV}$ prototype kicker pulser for proton radiography. The architecture is very similar to that of the DARHT kicker pulser.

The output of the prototype system is shown in Figure 24 . 


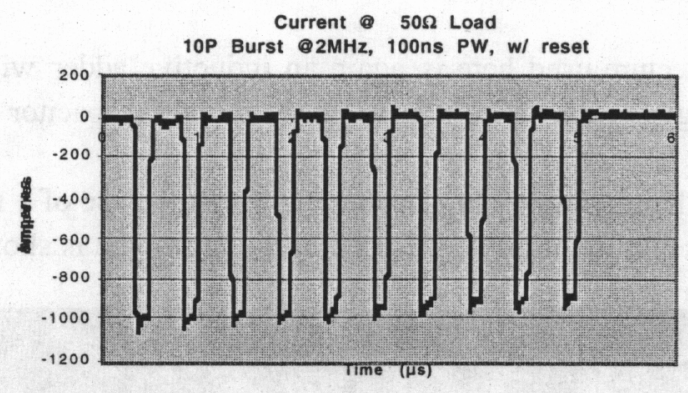

Figure 24. A 10 -pulse burst at $2 \mathrm{MHz}$. The current into a $50 \Omega$ load is plotted vs. time. The amplitude of the burst sags because the capacitor bank is insufficiently large for this burst.

\section{NLC Klystron Drivers}

Due to the tremendous advances in solid-state devices and in their performance to cost ratio many new applications are possible. For several years a joint SLAC-LLNL-Bechtel Nevada effort has been devoted towards developing solidstate drivers for klystrons to be used in the SLAC version of the NLC (Next Linear Collider). A system concept is shown in Figure 25.

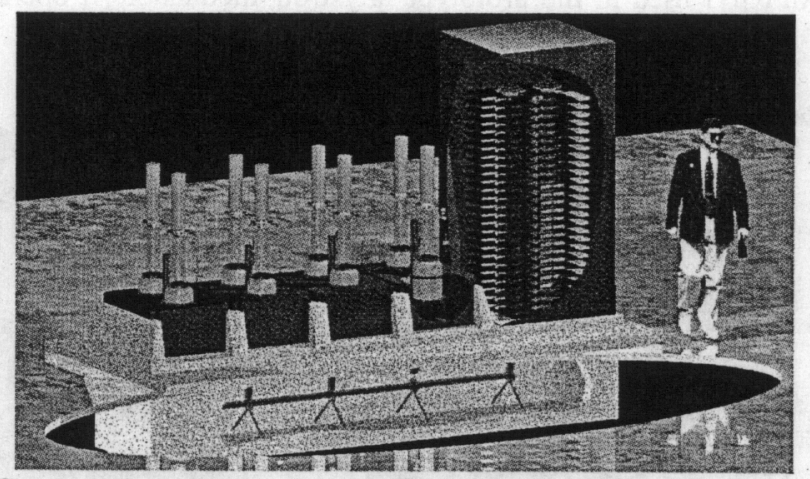

Figure 25. Concept for a solid-state pulser capable of driving 8 klystrons. The modulator is to put out $500 \mathrm{kV}$ at $2 \mathrm{kA}$.

\subsection{Solid-State Devices and Architecture}

Cost and robust operation are important considerations for this design. The modulator must be able to drive 8 high power klystrons at $120 \mathrm{~Hz}$ continuously and must supply $500 \mathrm{kV}$ at $2 \mathrm{kA}$. Large IGBT (Insulated Gate Bipolar 
Transistor) array devices used for traction control were chosen for this modulator.

The architecture used here is again an inductive adder with one switching layer per Metglas core. Each layer has its own capacitor bank and IGBT switches.

The modulator achieves high voltage through the use of a novel 1:3 step-up transformer. A picture of an IGBT used in the prototype is shown in Figure 26.

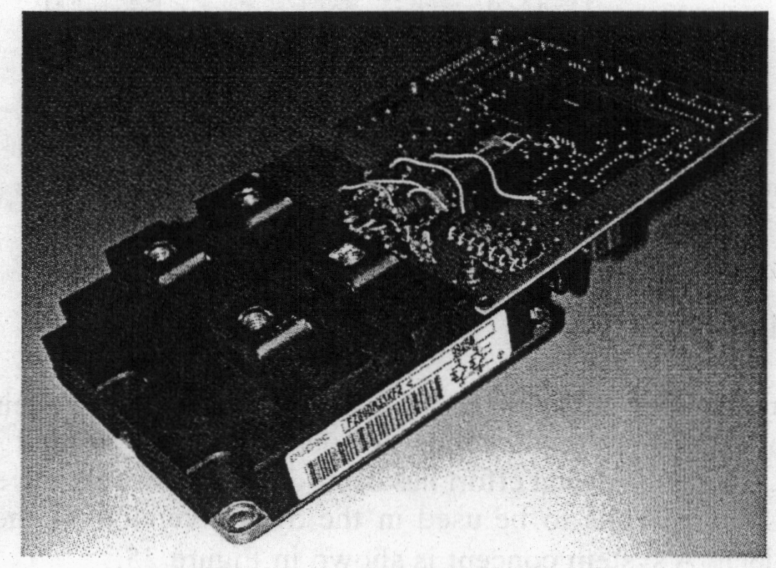

Figure 26. An IGBT used in the prototype klystron modulator. It operates at $3.3 \mathrm{kV}$ and 800 Amps (manufactured by EUPEC).

The completed prototype is shown in Figure 27.

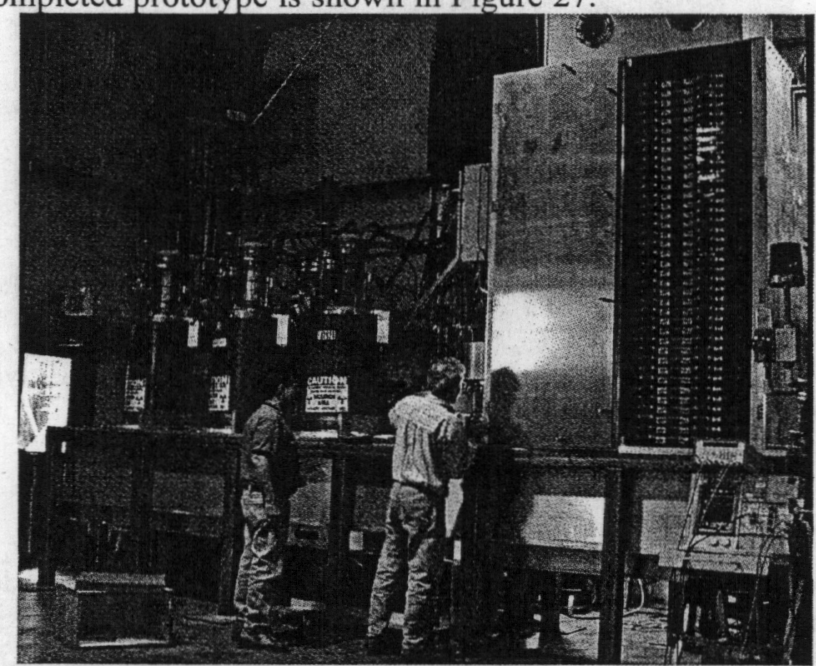

Figure 27 . The completed prototype klystron modulator. 


\section{High Gradient Insulators}

The next technology innovation to be discussed is that of high gradient insulators. These insulators might lead to the development of compact, high current accelerators and power sources.

\subsection{Insulator Flashover}

Vacuum insulators eventually breakdown along their surface as the tangential electric field stress is increased. Conventional insulators are generally monolithic structures and the breakdown is thought to be the result of a secondary emission electron avalanche where electrons are field emitted at the negative end of the insulator surface and drift in the vacuum along the insulator surface. ${ }^{4}$ Since the insulator is a dielectric it becomes polarized by the fieldemitted electron that leads to a collision of the electron with the surface. The collision stimulates the desorption of gas contaminants stuck to the surface and also leads to the emission of additional electrons. These electrons continue to drift and collide with the surface, increasing the number of electrons drifting and gas molecules that are desorbed until the gas density is sufficiently dense that an avalanche breakdown occurs and the voltage across the insulator collapses.

To slow this process one might introduce intermediate electrodes into the insulator (that protrude past the surface) on a scale sufficiently fine to interrupt the electron avalanche. The scale size for this is typically on the order of a millimeter. This is illustrated in Figure 28.

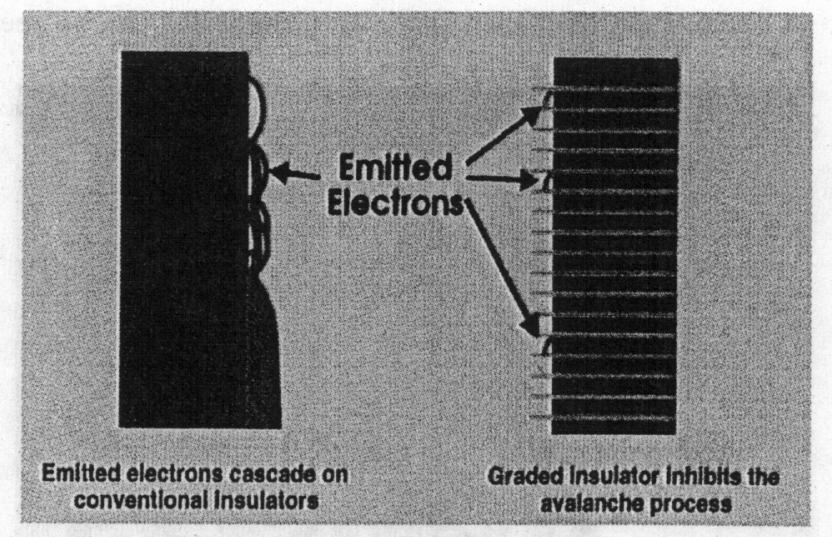

Figure 28. Flashover mechanism of a conventional insulator (left) showing the secondary emission electron avalanche. On the right is shown the concept of the high gradient insulator with closely spaced electrodes protruding past the surface designed to interrupt the electron avalanche. 
These insulators have been fabricated from materials such as ${ }^{\bullet}$ Lexan, Rexolite, Kapton, fused silica, Mycalex and alumina. The performance of these insulators has significantly exceeded that of conventional insulators. A comparison of conventional and high gradient insulator performance is shown in Figure 29.

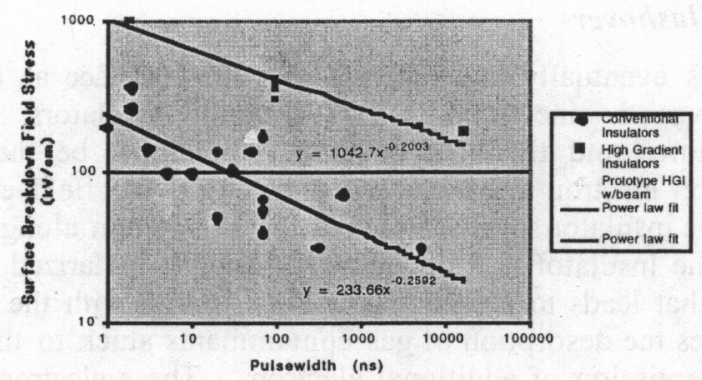

Figure 29. Comparison of conventional insulator performance (blue curve and points) and high gradient insulator (purple) performance vs. pulsewidth.

From Figure 29. we can see a general trend for all types of insulators; the surface flashover strength increases for shorter pulsewidths. A sample composed of Rexolite and stainless steel electrodes with a period of $0.25 \mathrm{~mm}$ was tested in a vacuum chamber between highly polished electrodes with a Rogowski profile. A Marx bank that could provide pulses on the order of 1-3 ns long powered the electrodes. A photograph of the insulator and electrodes can be seen in Figure 30 .

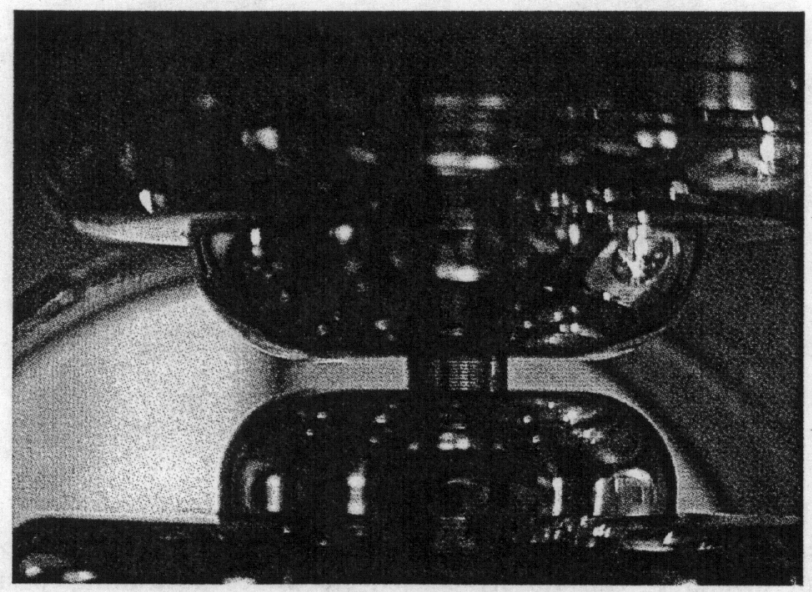


Figure 30. High gradient insulator test apparatus showing the Rogowski profile electrodes and the Rexolite/stainless steel sample. The insulator electrode spacing is $0.25 \mathrm{~mm}$. The sample shown is $3 \mathrm{~mm}$ high by $10 \mathrm{~mm}$ in diameter.

A typical voltage measured across the sample is shown in Figure 31. This particular data point corresponds to a field stress of $70 \mathrm{MV} /$ meter.

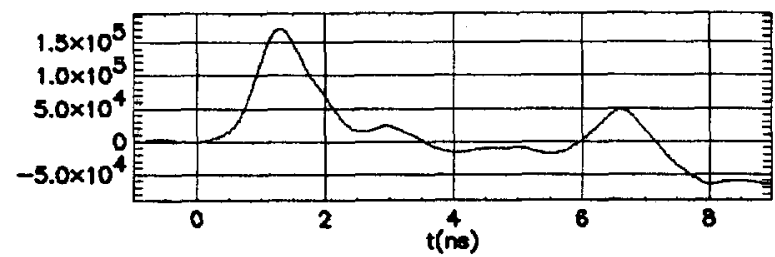

Figure 31. Voltage measured across the sample shown in Figure 30. This measurement corresponds to $70 \mathrm{MV} /$ meter field stress with no breakdown.

In order to apply maximum field stress to the insulator some of the layers were removed to increase the field stress. The resulting increase in capacitance widened the pulse somewhat to about 3 ns. There was still no breakdown at a stress of $100 \mathrm{MV} /$ meter.

Another interesting test concerns the ability of the high gradient insulator to sustain high field stresses in the presence of a high current electron beam. For this test the conventional insulator in one of our ETA-II induction cells was replaced with a high gradient version and the gap redesigned in order to have a direct line of sight from the beam to the insulator. The standard induction cell is shown in Figure 32.

As can be seen from Figure 32 the insulator is slanted away from the cathode side to discourage electron hopping along the surface. The length of the insulator across the slanted face is $3.75 \mathrm{~cm}$. Notice also that the insulator is shielded from a direct line of sight to the beam by the twisted gap geometry. 


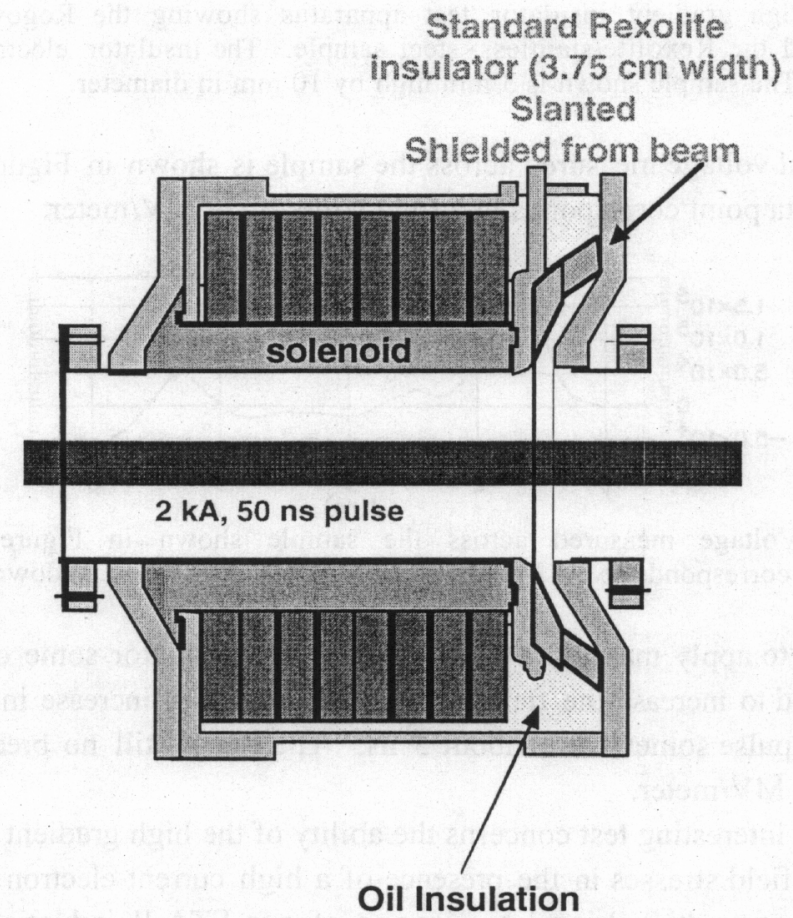

Figure 32. Standard ETA-II accelerator cell showing the slanted, monolithic Rexolite insulator.

The modified ETA-II cell is shown in Figure 33. It has a high gradient insulator made from Rexolite and stainless steel electrodes. The replacement insulator is only $1 \mathrm{~cm}$ in axial length and has a straight wall. In addition, the gap structure is purely radial providing a direct line of sight to the $6 \mathrm{MeV}, 2 \mathrm{kA}$, 50 ns wide ETA-II beam. 


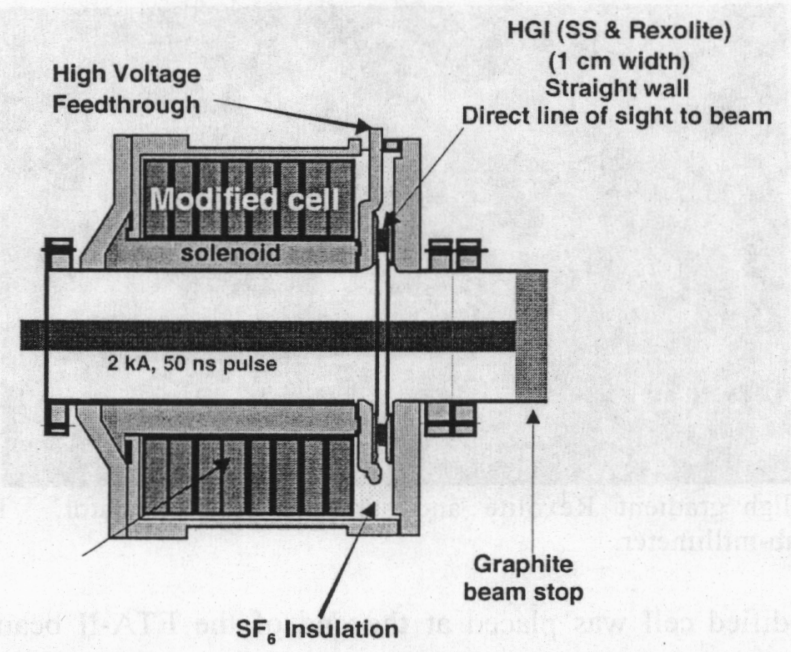

Figure 33. Modified ETA-II cell with a high gradient insulator. The insulator is only $1 \mathrm{~cm}$ in axial length as is straight with a direct line of sight to the beam.

The standard and high gradient insulators are shown in Figures 34. and 35. respectively.

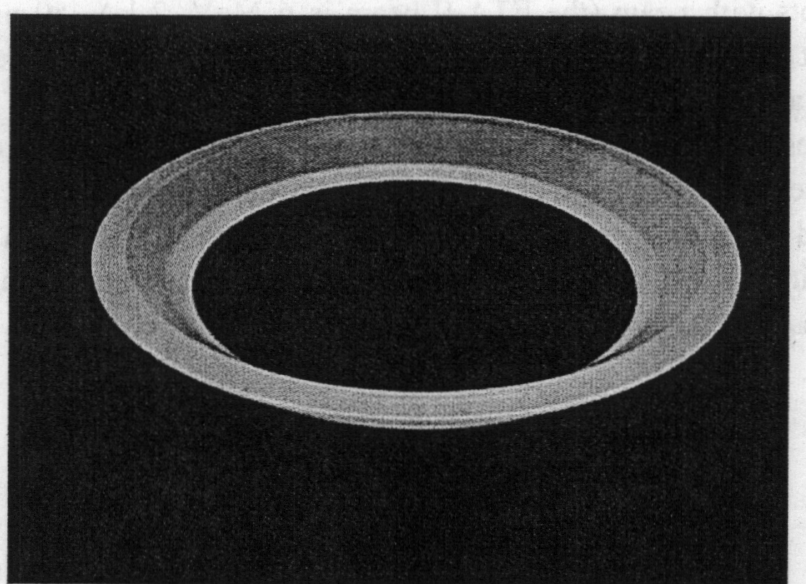

Figure 34. Standard Rexolite insulator in the ETA-II induction cell. Note the slanted surface. 


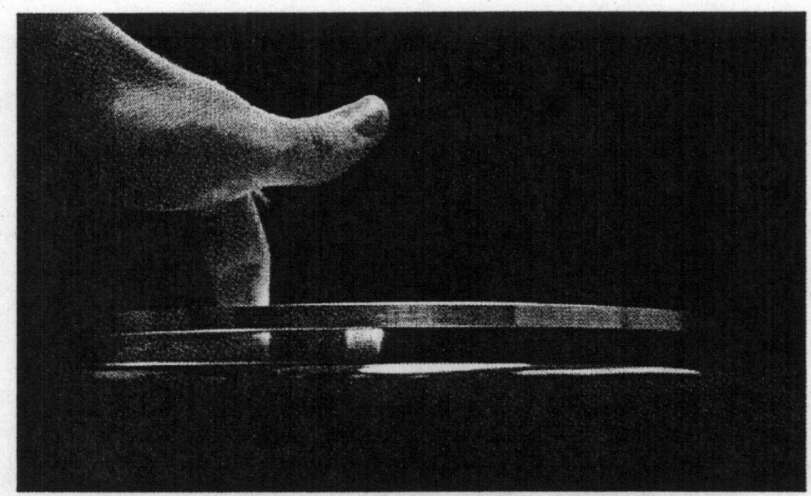

Figure 35. High gradient Rexolite and stainless steel insulator. The electrode spacing is sub-millimeter.

The modified cell was placed at the end of the ETA-II beamline with a graphite beam stop bolted to the cell. The cell was powered by the beam return current that flows through the drive blades. Various resistors were connected to the drive blades and created a reverse voltage across the gap. The resistor values were adjusted upwards in an attempt to reach an insulator breakdown. Attempts to reach breakdown levels failed. The insulator did not breakdown with over 20,000 shots with beam (the ETA-II beam is $6 \mathrm{MeV}, 2 \mathrm{kA}, 50 \mathrm{~ns}$ at $1 \mathrm{~Hz}$ ) at the highest resistor value tried. The volt-second content of the cell cores was too low to attempt higher voltage operation.

This result is rather remarkable given that the insulator has a direct line of sight to the beam and the beam is dumped at the end of the cell. There is a background of secondary electrons, $\mathrm{x}$-rays and optical photons all present in close proximity to the insulator. An overlay of voltage traces on the cell for different resistor values can be seen in Figure 36. 


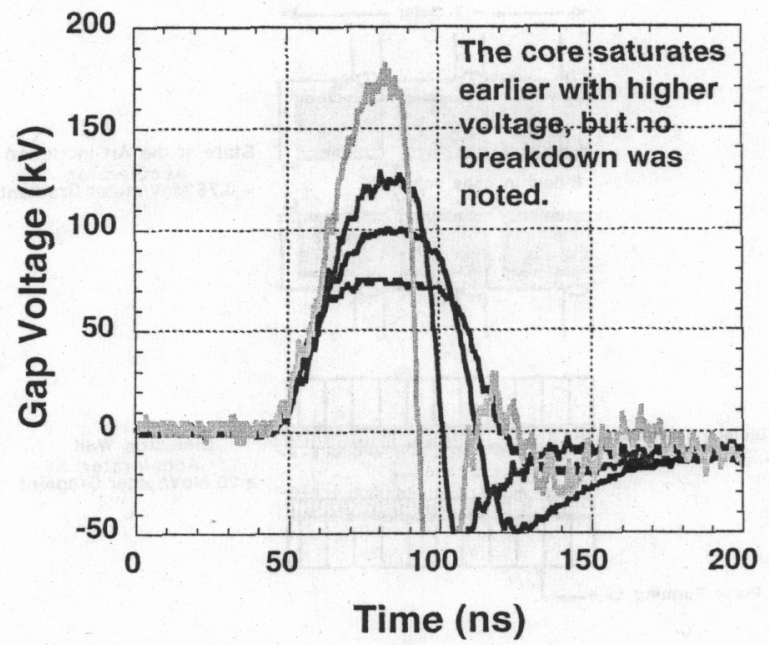

Figure 36. Voltage traces from the modified ETA-II cell. The lowest trace (red) is about the voltage that the cell is normally run at (about $80 \mathrm{kV}$ ). The upper trace corresponds to approximately $18 \mathrm{MV} /$ meter with no breakdown in the presence of a 2 $\mathrm{kA}, 50 \mathrm{~ns}$ electron beam. Note that the pulsewidths are shorter for the higher voltage traces due to core saturation.

\section{Dielectric Wall Accelerator (DWA)}

The performance of the high gradient insulator suggests that it might be possible to make compact, high current accelerators. The motivation for this is illustrated in Figure 37. that compares a conventional induction linac structure with that of a DWA. 


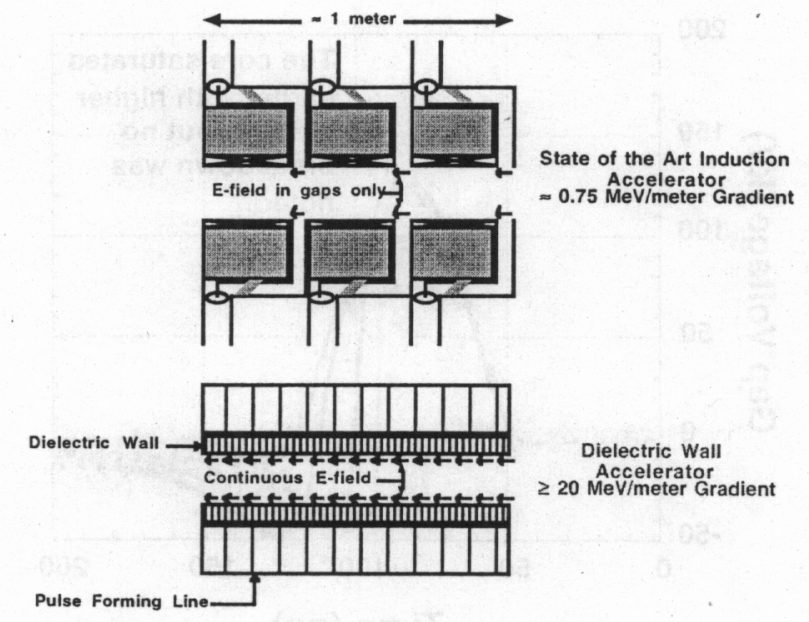

Figure 37. DWA concept. An induction linac can sustain an accelerating gradient only at the gap (typically of order $10 \mathrm{MV} /$ meter) but the gradient averaged over the entire structure is usually less than $1 \mathrm{MV} /$ meter. If the conducting wall were to be replaced by a suitable insulator perhaps the gradients achievable in the gaps could be sustained over the entire accelerator.

Figure 37. suggests that it might be possible to obtain much higher gradients than an induction linac with a DWA if a suitable insulator material could be identified. The second major requirement is that a method must be found to supply the dielectric wall with an accelerating field at the high gradient.

\subsection{Asymmetric Blumlein}

One method of generating a suitable accelerating field is called the asymmetric Blumlein invented by Bruce Carder. ${ }^{5}$ The line consists of two transmission lines (depicted as radial lines in the figure) that are filled with dielectrics of different permittivity. Both lines are initially charged to the same voltage but with opposite polarity. At first there is no net voltage across the output end of the lines (inner diameter). If the outside of the lines are shorted by closing switches, waves will be launched that travel radially inwards with different speeds. When the faster of these two waves reaches the inner diameter there will be a reflection of the wave accompanied by a net voltage reversal in that line. The voltage at the output end of the other line, however, is still equal to the original charge voltage since the slower wave has not yet reached that point. At that instant a net voltage appears across the output end of both lines. That net voltage is maintained until the slower wave reaches the output end of the line 
and collapses the net voltage. Since the line is not $100 \%$ efficient there will be multiple reflections and ringing of the output waveform. The output waveform can be applied across a high gradient insulator. This process is illustrated in Figure 38.

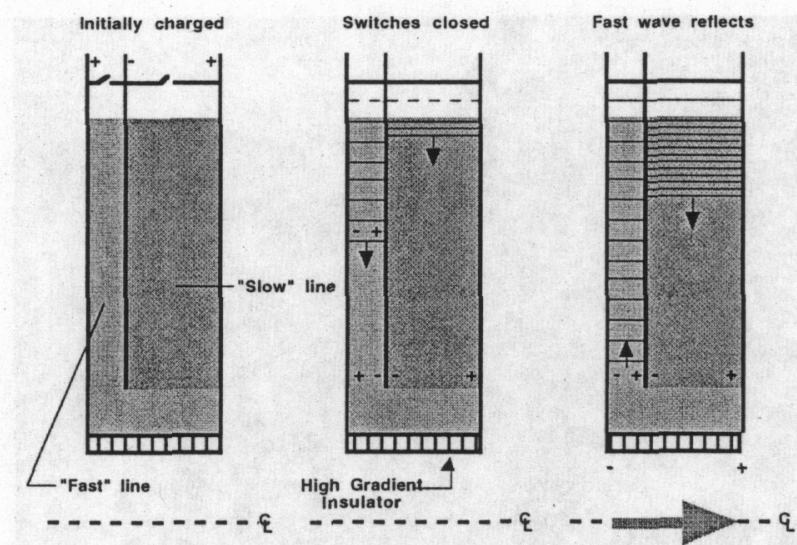

Figure 38. Operation of the asymmetric Blumlein. The line is formed from radial transmission lines containing material of different permittivities and charged to equal and opposite voltages. Closing switches on the outer diameter of the lines launch the accelerating pulse will eventually appears on the high gradient insulator at the inner radius.

\subsection{Laser-Induced Flashover Switch}

A suitable closing switch can be obtained by using a flux of photons to bombard the outer vacuum surface of each charged transmission line in Figure 38. The photon flux will initiate a flashover of the vacuum surface, which provides an effective switch closure. A fast photon flux is available from a laser (a Nd-Yag laser with frequency doubling or tripling crystals is used). This is illustrated in Figure 39.

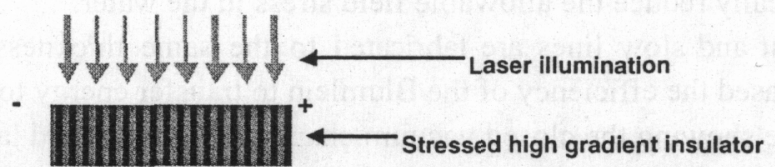

Figure 39. A fast laser pulse initiates a vacuum surface flashover across a highly stressed insulator, providing an effective switch closure.

\subsection{Test of Asymmetric Blumlein}

The operation of an asymmetric Blumlein was tested using a cross configuration consisting of four, equal width striplines that intersect at their output ends. The materials employed were de-ionized water for the slow line 
and RT-Duroid, a printed circuit laminate, for the fast line. The Blumlein was placed inside a chamber to provide vacuum on the outer and inner surfaces. The Blumlein in the chamber is shown in Figure 40.

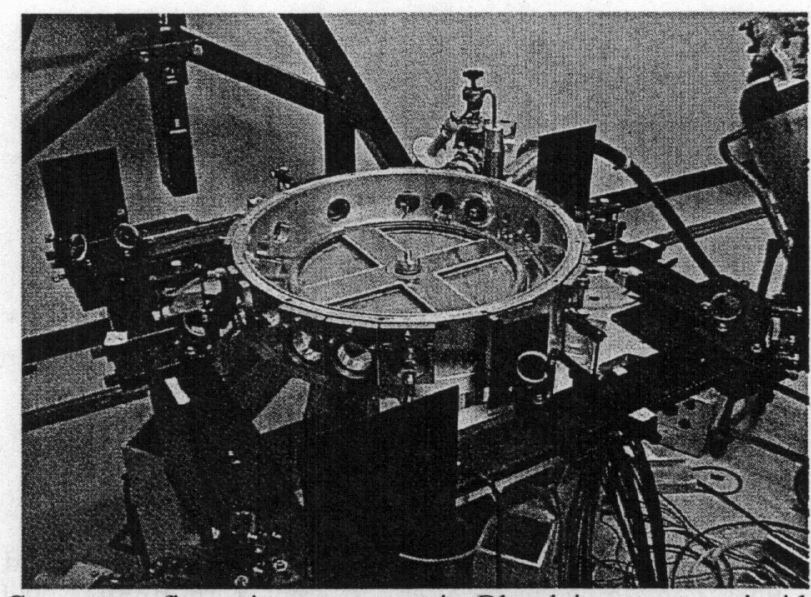

Figure 40. Cross configuration asymmetric Blumlein structure inside its vacuum chamber. Note the optical ports and mirrors for the laser beams that trigger the acceleration waveforms.

The system is pulse-charged (since de-ionized water cannot hold a charge for very long) and triggered by four laser beams, one for each stripline.

A frequency tripled Nd-Yag laser is used for the triggering. The optical paths are arranged so that the four beams arrive simultaneously at the stripline edges. Conventional Rexolite insulators are used on the inner and outer surfaces for these first tests. A voltage probe is inserted into the inner diameter of the inner insulator to measure the output voltage.

The water had to be filtered and de-gassed to suppress bubble formation that would drastically reduce the allowable field stress in the water.

Both fast and slow lines are fabricated to the same thickness, a fact that further decreased the efficiency of the Blumlein to transfer energy to the load.

A picture showing the closed vacuum chamber and simulated laser beams is shown in Figure 41. 


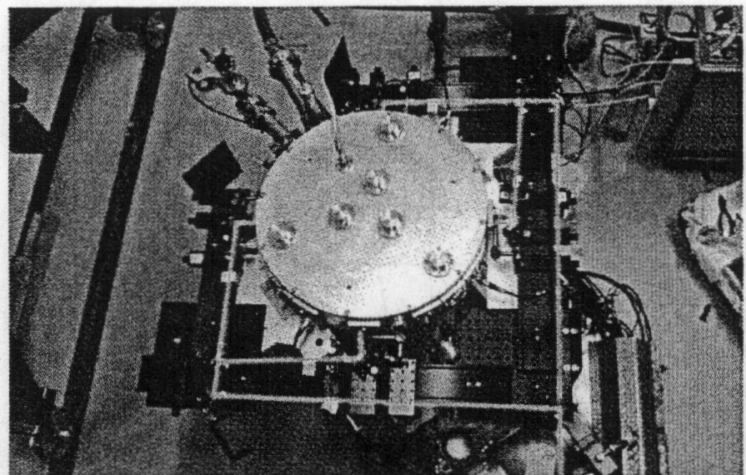

Figure 41. Closed vacuum chamber with simulated laser beams. The four beams arrive at their respective striplines simultaneously.

The output field stress achieved exceeded $5 \mathrm{MV} /$ meter. An output voltage trace from the monitor is shown in Figure 42.

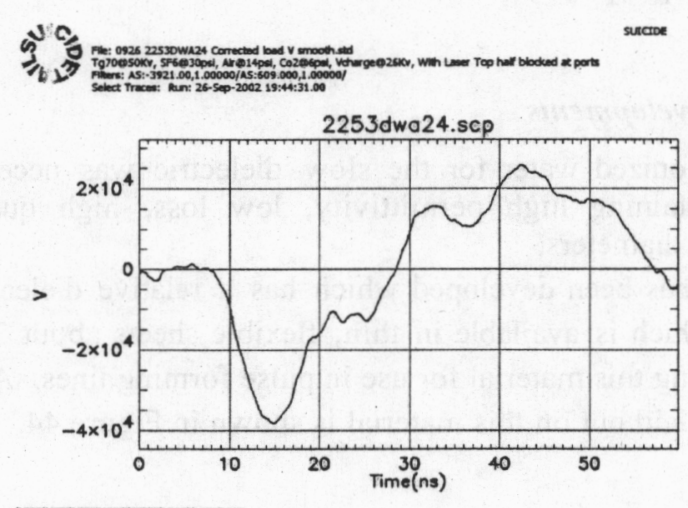

Figure 42. Output voltage from a single asymmetric Blumlein.

Two Blumleins were stacked in the vacuum chamber. The results are shown in Figure 43 below. 


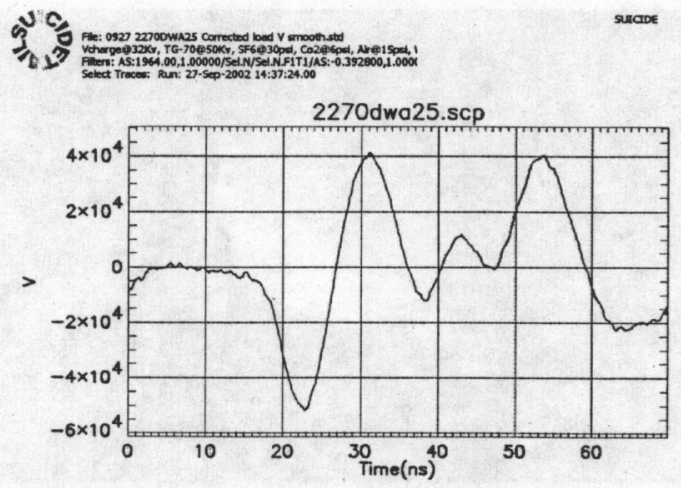

Figure 43. Results from a stack of two asymmetric Blumleins.

The outputs of the lines are not matched to the loads, which results in excessive ringing. In practice, the first (negative) part of the waveform would constitute the output pulse.

\subsection{Future Developments}

The use of de-ionized water for the slow dielectric was necessitated by the difficulty in obtaining high permittivity, low loss, high quality insulating material in large diameters.

A material has been developed which has a relative dielectric constant of about 30 and which is available in thin, flexible sheets about 36 inches wide. We are developing this material for use in pulse forming lines. An example of a curved stripline laid out on this material is shown in Figure 44. 


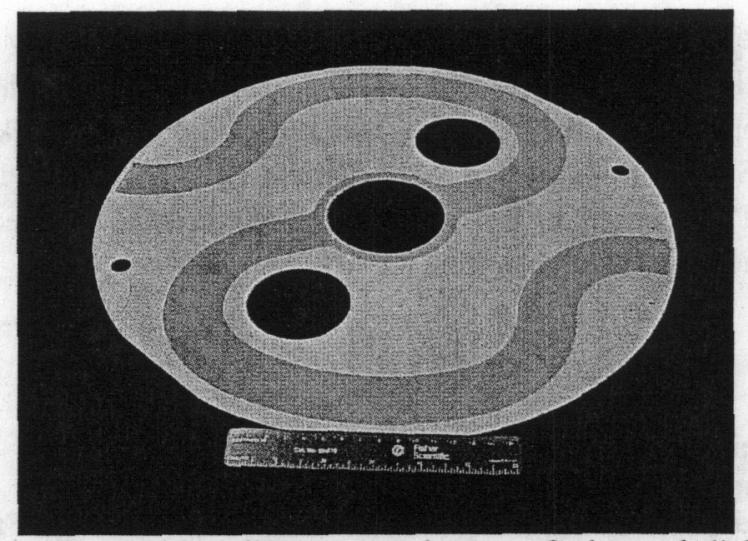

Figure 44. A pair of curved striplines on a substrate of advanced dielectric material of relative permittivity 30 .

This pair of lines will be used as the slow lines in combination with a lower dielectric material like Lexan as shown in Figure 45.

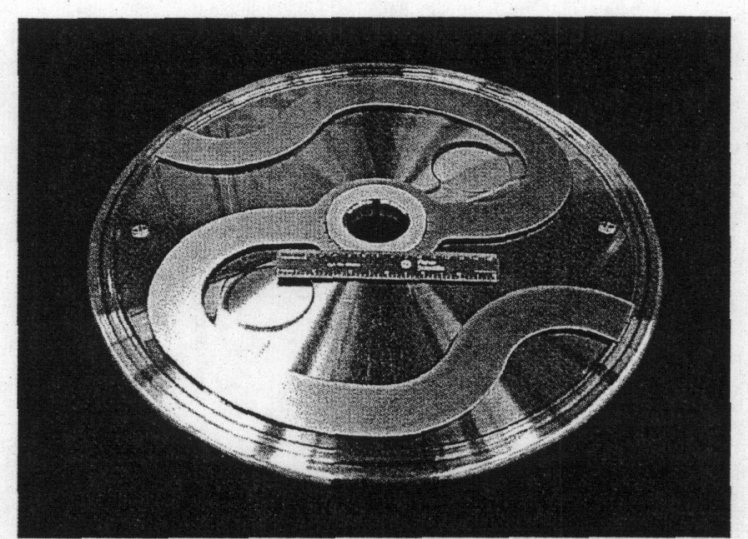

Figure 45. A pair of curved striplines on Lexan providing the fast lines to match the slow lines in Figure 44.

Using solid dielectrics will enable the use of slow charging systems since these materials will hold a charge for a very long time.

\section{Acknowledgments}

Many people contributed to the work that has been reported here. The original development of the solid-state architecture was done by Hugh Kirbie, then at LLNL. The modern development of this architecture for kicker pulser and 
klystron driver applications is due to Ed Cook of LLNL. Judy Chen and Jim Watson developed the fast kicker and its control system while John Weir oversaw the operation of the ETA-II accelerator on which the kicker system was developed. Steve Sampayan led the experimental work on the Dielectric Wall Accelerator. I am grateful to Rollin Whitman, the DARHT Project Director, for material on the DARHT accelerators.

\section{References}

1. G. J. Caporaso, Linear Induction Accelerator Approach for Advanced Radiography, PAC 97, Vancouver, B. C., May 1997.

2. Y. J. (Judy) Chen, G. J. Caporaso, J. T. Weir, Precision Fast Kickers for Kiloampere Electron Beams, PAC 99, New York March 1999.

3. G. E. Hogan, et. al., Proton Radiography, PAC 99, New York March 1999.

4. R. A. Anderson and J. P. Brainard, J. Appl. Phys. 51(3) (1980) 1414.

5. B. M. Carder, U. S. Patent No. 5757146, May 26, 1998. 